ISSN 1518-3483

Licenciado sob uma Licença Creative Commons

\title{
Profissão docente e a formação dos formadores: relações entre a universidade e a educação básica
}

\author{
Teaching profession and the training of trainers: relations \\ between the university and basic education
}

\author{
Ana Lara Casagrande, Joyce Mary Adam*
}

Universidade Estadual Paulista “Júlio de Mesquita Filho" (UNESP/Rio Claro), São Paulo, SP, Brasil

\section{Resumo}

Este trabalho apresenta resultados oriundos da tese intitulada "Gestão pública da educação paulista: a carreira docente e o novo Ensino Médio", desenvolvida no âmbito da UNESP/Rio Claro, que envolveu um estudo sobre a carreira docente e a reconfiguração da mesma no projeto Escola Estadual de Ensino Médio de Período Integral, desenvolvido no Estado de São Paulo. O objetivo deste artigo é pensar a profissão docente tanto do ponto de vista do campo universitário quanto do contexto relativo à educação básica, para isso, discute-se por meio do levantamento e de análise bibliográfica: a questão dos saberes dominados pelos professores; a formação inicial; a formação em outro(s) espaço(s) que não o das universidades, centros universitários e faculdades, problematizando a proliferação de cursos que especificamente se prestam à finalidade da formação contínua. Nesse sentido, há questões centrais a serem consideradas: o que se pode entender

* ALC: Doutora em Educação, e-mail: larabighouse@yahoo.com.br JMA: Doutora em Educação, e-mail: jpyce@rc.unesp.br 
por saberes docentes? A formação inicial e continuada dos docentes é fundamental para sua prática? Uma formação pela prática é possível? Os resultados obtidos indicam avanços nos estudos sobre a expertise docente e problemas relacionados ao lucrativo discurso da formação continuada. Elementos que devem ser ainda mais debatidos em função das perspectivas futuras da formação e da própria carreira do magistério.

Palavras-chave: Formação inicial. Formação continuada. Docência. Universidade. Educação Básica.

\section{Abstract}

This paper presents coming results of the thesis entitled "Public Management from the state education: teaching career and the new high school," developed at UNESP/Rio Claro, which involved a study of the teaching profession and its reconfiguration in the High School project of Full Time, developed in São Paulo. The purpose of this article is to think the teaching profession from the point of view of the university campus as the context on basic education, for this, it is argued by the survey and literature review: the question of knowledge dominated by teachers; initial training; training in other areas other than the universities, university colleges and centers, discussing the emergence of courses that specifically lend themselves to the purpose of training. In this sense, there are core issues to consider: what can be understood by teaching knowledge? Initial and continuing training of teachers is essential to your practice? Training the practice is possible? The results indicate advances in studies on the teaching expertise and problems on the profitable discourse of continuing education. Elements that should be better discussed in terms of future prospects of the formation and the teaching career.

Keywords: Initial training. Continuing education. Teaching. University. Basic education.

\section{Introdução}

Os resultados apresentados neste artigo provêm da pesquisa de doutorado intitulada "Gestão pública da educação paulista: a carreira docente e o novo Ensino Médio", desenvolvida no âmbito da UNESP/Rio 
Claro, que envolveu um estudo sobre a carreira docente e a reconfiguração da mesma no projeto Escola Estadual de Ensino Médio de Período Integral, desenvolvido no Estado de São Paulo. Neste texto, pretende-se pensar na docência tanto do ponto de vista do campo universitário quanto do contexto relativo à educação básica. Os avanços da pesquisa tangem ao olhar crítico sob a formação, relacionando-a a qualidade da educação, mas também ao desinteresse pela carreira do magistério, sendo que por meio da formação cuja materialidade se dá dentro da docência esse instituto poderia contribuir duplamente: valorização dos professores que já atuam nessa etapa e formação continuada mais sólida e significativa.

\section{Metodologia}

Buscando diferenciar o levantamento e análise da revisão bibliográfica, Lima e Mioto (2007, p. 44) assinalam que a primeira "[...] difere da revisão bibliográfica uma vez que vai além da simples observação de dados contidos nas fontes pesquisadas, pois imprime sobre eles a teoria, a compreensão crítica do significado neles existente".

Lakatos e Marconi (1992, p. 44) afirmam que esse procedimento permite o levantamento do estudo da questão em análise a todas as pesquisas, de modo que "[...] pode, portanto, ser considerada também como o primeiro passo de toda pesquisa científica". O que também acontecerá com a pesquisa "Gestão Pública da Educação Paulista: as Políticas de Carreira Docente e o Novo Ensino Médio".

Salvador (1986) enfatiza a necessidade, ao realizar o levantamento e análise bibliográfica, de que o pesquisador realize leituras sucessivas do material para obter as informações necessárias à pesquisa. Desse modo, o autor reconhece alguns momentos fundamentais.

O primeiro seria a leitura de reconhecimento do material bibliográfico definido como uma leitura rápida, que objetiva localizar e selecionar o material que pode apresentar informações referentes ao tema (SALVADOR, 1986). 
Uma segunda fase também de leitura rápida, Salvador (1986) chama de leitura exploratória, cujo objetivo é verificar se as informações selecionadas interessam, de fato, para o estudo. A leitura seletiva é aquela que definitivamente procura determinar o material o qual realmente interessa à pesquisa, por isso, é o momento em que as obras são diretamente relacionadas aos objetivos da pesquisa e as informações secundárias ou irrelevantes são descartadas (SALVADOR, 1986).

Um aprofundamento dessa etapa se dá com o que Salvador (1986) denomina leitura reflexiva ou crítica. Ela corresponde a um estudo crítico do material, sendo realizada nos textos escolhidos como definitivos e com o intuito de responder aos objetivos da pesquisa.

A última etapa do processo de leitura se efetua, conforme indica Salvador (1986), com a leitura interpretativa, caracterizada como o momento mais complexo do levantamento documental, pois já incorpora a análise do material selecionado.

\section{Universidade e educação básica: caminhos que se cruzam, prestígio que as separa}

Parte-se do princípio de que há diferenciação quanto ao status dos docentes universitários e não universitários. Claro que o prestígio social é um conceito subjetivo à medida que não pode ser quantificado, mas não deve ser desconsiderado ao discutir-se trabalho, tendo em vista sua significância para a construção da profissionalidade e elevação do estatuto profissional. O prestígio "[...] tem relação direta com a centralidade e importância social do trabalho que executam e o momento em que os professores desempenham este papel" (FIDALGO, 1996, p. 100). O docente que trabalha no nível universitário tem um prestígio social superior aos demais educadores, o que inclui o da educação básica, que, por sua vez, tem um prestígio maior ao conferido ao que leciona na educação infantil: "As tentativas de incluir toda a docência em uma categoria única 
- trabalhadores em educação - não conseguiram unificar os modos de ser e de ver a docência como professores" (ARROYO, 2007, p. 201).

Uma hipótese para entender esse fenômeno, mas não de explicá-lo, relaciona-se à diferença de reconhecimento social entre os saberes que os docentes mobilizam nas diferentes etapas de ensino. Esse reconhecimento seria positivo, não fosse o fato de acreditarem, inapropriadamente, que a educação infantil, por exemplo, necessite de saberes menos elaborados ou que seja uma tarefa de mais fácil execução.

Há uma possibilidade, em outro sentido, de não ser a complexidade dos saberes o motivo da diferenciação de prestígio, mas, em que se apoiam os conhecimentos de que os docentes lançam mão. No caso dos docentes do ensino superior, por exemplo, eles se apoiam em conhecimentos aprovados profissionalmente, por seus pares. Inclusive, Freidson (1998) aponta a universidade como um espaço que permite aos estudiosos, cientistas e intelectuais serem considerados profissionais, já que controlam o recrutamento, treinamento e emprego de seus membros, estudando a questão do conhecimento, não apenas ensinando-o.

No caso brasileiro das universidades públicas, os pares participam do recrutamento e avaliação nos anos iniciais do exercício da profissão, o emprego fica a cargo do Estado. Os candidatos a docentes das instituições de ensino superior públicas devem participar de um concurso público para ingressar na carreira, aberto por meio de edital, que normalmente é composto de prova escrita, prova didática, memorial e análise de Títulos. O processo normalmente é conduzido, apreciado e avaliado por docentes da própria universidade.

Cabe problematizar se, de fato, os docentes do ensino superior são valorizados ou se seu crédito vem do fato de serem concomitantemente pesquisadores. Cunha (2009) se posiciona no sentido afirmativo à segunda questão, acrescentando elementos para discutir-se o Ensino Superior, assim, afirma que sua especificidade está em assentar sua base profissional ao mundo do trabalho prático e na pesquisa: "[...] o que concede prestígio, nesse nivel de ensino, não tem sido os saberes da docência, mas especialmente 
as competências relacionadas com a pesquisa, campo onde, em geral, não se incorpora a dimensão pedagógica (CUNHA, 2009, p. 84, grifo nosso).

Nas discussões sobre o papel da universidade, há defesas no sentido de que para atingir a noção de "universidade de ponta", flagship university, deva-se fortalecer a pesquisa científica e tecnológica. Schwartzman (2006, p. 161, grifo nosso), por exemplo, considera que na América Latina as universidades demoraram a incorporar o componente de pesquisa, "[...] de tal modo que, ainda hoje, nos debates sobre quais devem ser as prioridades de uma universidade, a pesquisa é obrigada a competir com outros valores e outras motivações".

A posição de Schwartzman (2006, p. 162) desconsidera a universidade como espaço de formação de professores e a realça como espaço de desenvolvimento e divulgação de programas de pesquisa, o que fica claro ao dar o exemplo da Universidade de São Paulo (USP), afirmando que ela não é amplamente conhecida no âmbito internacional e não está bem colocada em diversos rankings internacionais de universidades publicados recentemente, o que para o autor é "[...] resultado da falta de um esforço explícito da universidade e das autoridades públicas para torná-la uma influente instituição de pesquisa de classe internacional".

É possível que, ao escrever, o autor se refira aos cursos de Bacharelado e não aos de Licenciatura, no entanto, considera-se impossível ignorá-los, sem descaracterizar a abrangência e importância da universidade citada, que conta com 26 cursos de Licenciatura e das demais universidades públicas brasileiras. Tornar a USP uma universidade reconhecida internacionalmente estaria em consonância, para o autor, com os objetivos iniciais com os quais foi criada: "[...] desenvolver competência profissional e conhecimento aplicado para fazer crescer a economia, o que de fato ocorreu" e "trazer civilização ao Brasil por meio da 'ciência pura' e do 'pensamento puro'" (SCHWARTZMAN, 2006, p. 165).

A supervalorização da pesquisa é um elemento que dificulta a discussão a respeito do papel da universidade na formação inicial, pois alguns professores universitários, identificados no título deste artigo como formadores, dada a sua função de formar os futuros professores, não se dão conta 
da importância de seu papel. Cabe lembrar que todos os docentes em exercício no ensino superior público no Brasil têm a atividade de ensino como uma das funções a serem desenvolvidas, estejam vinculados aos cursos de Bacharelado ou Licenciatura. Ainda mais por conta do segundo tipo de graduação, o ensino não deve, na ótica deste trabalho, ter um papel secundário na universidade, pois a formação inicial de professores se dá neste espaço, isto é, na universidade está o professor formador de professores.

Como hipótese última para o desprestígio dos docentes que atuam na educação infantil, conjectura-se o fato dessa etapa de ensino, em seus primórdios, estar ligada ao atendimento das classes menos desfavorecidas, o que pode sugerir resquícios de um estigma. Como afirma Correa (2007, p. 15): "[...] o atendimento à infância no Brasil teve seu início marcado pela ideia de 'assistência' ou 'amparo' aos pobres e 'necessitados' [...]”.

A defesa aqui é a de que não procede a supremacia do docente de um nível de ensino sob o outro, pois isso impede entender a universidade e as escolas de educação básica como espaços privilegiados de formação e que devem retroalimentar-se, em uma perspectiva colaborativa. No entanto, é preciso avançar na ideia de universidade como espaço de formação e abandonar o pressuposto do paradigma tradicional de transmissão do conhecimento, que não tem mostrado "[...] historicamente, uma preocupação significativa com os conhecimentos pedagógicos (CUNHA, 2010, p. 28).

A ligação entre as universidades e as escolas é um dos elementos defendidos pelo Grupo Holmes (1995) para a estruturação da profissão docente. Analogamente ao que ocorre em hospitais na profissão médica, a proposta é a de que os professores universitários e da educação básica atuem em parceria, com base na reciprocidade ou troca mútua de benefício entre pesquisa, prática e experimentação, ou vontade de experimentar novas formas de prática e estrutura de investigação sistemática, comprometidas com o desenvolvimento de estratégias de ensino para as crianças de diferentes origens, habilidades e estilos de aprendizagem (HOLMES GROUP, 1995).

Outro aspecto que perpassaria a reforma da profissão docente para atingir um estatuto profissional, seria o reconhecimento de 
diferenças (conhecimento, habilidade e compromisso) entre os professores. Isto é, o Holmes Group (1995) propõe mudanças na estrutura da profissão, estabelecendo o desenvolvimento de uma estrutura diferenciada em três níveis: o Professor Profissional de Carreira, que seria capaz de assumir a responsabilidade, não só dentro da sala de aula, mas também em nível da escola, inclusive auxiliando os professores ingressantes; o Professor Profissional, que estaria preparado como um profissional totalmente autônomo em sala de aula; e o Instrutor, que estaria preparado para a instrução sob a supervisão de um Professor Profissional de Carreira (HOLMES GOUP, 1995).

Essa medida parece pertinente por dois motivos: primeiro porque, na educação básica, o professor experiente não progride na carreira, os mesmos desafios que tem ao entrar na carreira são os do final, é dizer, se exige dele as mesmas funções apesar da experiência e saberes que ele acumulou ao longo do tempo de trabalho; segundo, porque os professores ingressantes parecem atuar bastante instintivamente no início da carreira.

Uma questão problemática com relação ao ensino da educação básica no Brasil, que também atinge os Estados Unidos, e relaciona-se à regulação da entrada de professores na profissão, é o aumento de alunos inversamente proporcional ao número de professores e à demanda crescente. Falar em regular a entrada diante do que se chama de crise das licenciaturas e falta de professores no Estado de São Paulo, por exemplo, pode soar como loucura.

Para promover uma reforma na docência, o Grupo Holmes (1995) propõe que as escolas se tornem lugares melhores para a prática e a aprendizagem dos professores. O que poderia ser efetuado pela mudança na estrutura existente nas escolas, nas condições de trabalho dos professores e na atual divisão de autoridade entre administradores e professores, os quais revelam uma falta de sintonia com as exigências da nova profissão (HOLMES GROUP, 1995).

Acredita-se, então, a necessidade de: uma parceria real entre escolas e universidades, que permita o intercâmbio mútuo entre a investigação e a prática; desenvolvimento de uma estrutura diferenciada 
para a oportunidade profissional; a criação de normas para a entrada na docência e o reconhecimento da escola como espaço de trabalho e de aprendizagem.

\section{A questão da formação: saberes docentes na educação básica}

Dada a importância dos saberes docentes, torna-se fundamental se compreender quais são, como se manifestam e como são articulados pelo professor os saberes, as técnicas e valores no contexto da sala de aula.

Antes de conceituar "saber(es)" e refletir sobre os saberes docentes, é interessante observar o argumento da incompetência, identificado por Souza (2006), usado para sustentar a crescente importância atribuída aos programas de formação contínua de professores, somados a um projeto que visava o avanço da qualidade das escolas.

Souza (2006) observa que essa preocupação com a competência ou a incompetência docente não é recente e, tecendo uma crítica, salienta que ele ganhou impulso a partir de uma publicação, em 1982, de um trabalho intitulado Magistério de $1^{\circ} \mathrm{Grau}$ : da competência técnica ao compromisso político, cuja autora foi Guiomar Namo de Mello. Essa publicação suscitou intensos debates na academia, pautada em dois conceitos que se relacionavam ao ofício de professor: compromisso político e competência técnica.

Ao analisar as representações dos professores, Mello (1982) afirma que eles atribuem a fatores externos à escola a responsabilidade pelo fracasso escolar das crianças. O que atenua sua influência e das instituições de ensino. A partir disso, a escola ressaltará a competência técnica como algo a ser estimulado na formação do professor (dado o que chama de deterioração da qualidade dos cursos de formação), que é incapaz de articular as causas intra e extraescolares para alterar positivamente (compromisso político) os índices de evasão escolar (MELLO, 1982).

Segundo Souza (2006), esse trabalho de Mello (1982) inspirou a realização de outros trabalhos que, intencionalmente ou não, 
contribuíram para proliferar uma visão negativa e homogênea dos professores, na qual eram considerados descompromissados socialmente e tecnicamente incompetentes.

Esse argumento da incompetência deve-se, em certa medida, à falta de imposição dos docentes da educação básica como grupo produtor de um saber oriundo da prática. Segundo Tardif (2010, p. 54), “[...] os saberes experienciais surgem como núcleo vital do saber docente”, eles seriam formados de todos os demais saberes.

Na mesma acepção de Tardif (2000, p. 10-11), consideramos os saberes em um sentido amplo, o "[...] que engloba os conhecimentos, as competências, as habilidades (ou aptidões) e as atitudes, isto é, aquilo que muitas vezes foi chamado de saber, saber-fazer e saber-ser". Não se deve confundir, então, saberes, como apenas aqueles iminentemente acadêmicos, adquiridos na formação inicial.

Tardif (2000, p. 13) apresenta algumas características dos saberes profissionais referentes aos docentes, sob o escopo da epistemologia da prática profissional, que sustentam a necessidade de se estudar o conjunto dos saberes mobilizados e utilizados pelos professores em todas as suas tarefas. Tais características ilustram a gama dos saberes profissionais docentes, originando-se das críticas de pesquisas empíricas sobre ensino nos Estados Unidos juntamente com as pesquisas empreendidas por Tardif a respeito dessa temática.

A primeira delas diz respeito à temporalidade dos saberes profissionais dos professores, isso significa dizer que tais saberes são adquiridos através do tempo. $\mathrm{O}$ autor faz essa afirmação referindo-se a três sentidos: os saberes docentes provêm de sua própria história de vida, sobretudo de sua história de vida escolar; os primeiros anos de prática profissional são decisivos na estruturação da prática profissional; os saberes profissionais são utilizados e desenvolvidos no âmbito de uma carreira, suscetível a dimensões indenitárias e de socialização profissional, fases e mudanças (TARDIF, 2000; 2010).

A segunda característica se refere à pluralidade e heterogeneidade dos saberes profissionais dos professores, também explicada em três 
sentidos: eles provêm de diversas fontes (história de vida, cultura escolar anterior adquiridos na universidade, programas, guias e manuais escolares, seu próprio saber ligado à experiência de trabalho, experiência de certos professores e tradições peculiares ao ofício de professor); são ecléticos e sincréticos, não são limitados a uma teoria ou uma concepção unitária de sua prática, são utilizadas muitas teorias, concepções e técnicas, conforme a necessidade; visam a diferentes objetivos, cuja realização não exige os mesmos tipos de conhecimento, competência e aptidão (TARDIF, 2000; 2010). Com relação à pluralidade e heterogeneidade dos saberes profissionais dos docentes, Tardif (2000) esclarece, comparativamente, que:

[...] se os saberes profissionais dos professores têm uma certa unidade, não se trata de uma unidade teórica ou conceitual, mas pragmática: como as diferentes ferramentas de um artesão, eles fazem parte da mesma caixa de ferramentas, porque o artesão pode precisar deles no exercício de suas atividades. A natureza da relação entre o artesão e todas as suas ferramentas é, portanto, pragmática: essas ferramentas constituem recursos concretos integrados ao processo de trabalho, porque podem servir para fazer alguma coisa específica relacionada com as tarefas que competem ao artesão (TARDIF, 2000, p. 15).

Outra característica dos saberes profissionais é que são personalizados e situados. Ou seja, são fortemente peculiares aos indíviduos, são saberes que não podem ser dissociados das pessoas, de suas experiências e situação de trabalho, conforme indica a pesquisa a respeito dos saberes profissionais.

Por fim, uma característica relevante diz respeito ao fato dos saberes dos professores carregarem as marcas do ser humano, dado seu objeto de trabalho (TARDIF, 2000).

A escola é um espaço onde crianças, jovens e adultos podem realizar seu desenvolvimento pessoal e intelectual. Mas é, sobretudo, o espaço onde o diálogo social é construído. Nesse sentido, o docente se torna uma figura central e a escola do início desse século XXI insubstituível, pois com a condução do primeiro nela se pode aprender a conviver e viver com as pessoas (NÓVOA, 2011). 
Tal reconhecimento traz implicações cruciais para a prática profissional docente, segundo Tardif (2000), pouco discutidas:

Em primeiro lugar, os seres humanos têm a particularidade de existirem como indivíduos. [...] Esse fenômeno da individualidade está no cerne do trabalho dos professores, pois, embora eles trabalhem com grupos de alunos, devem atingir os indivíduos que os compõem, pois são os indivíduos que aprendem. Do ponto de vista epistemológico, essa situação é muito interessante. É ela que orienta a existência, no professor, de uma disposição para conhecer e para compreender os alunos em suas particularidades individuais e situacionais, bem como em sua evolução a médio prazo no contexto da sala de aula. [...] A aquisição da sensibilidade relativa às diferenças entre os alunos constitui uma das principais características do trabalho docente (TARDIF, 2000, p. 16).

Já a segunda consequência do objeto humano do trabalho docente reside no fato do saber profissional relacionar-se a um componente ético e emocional, pois o ensino é uma prática profissional que produz mudanças emocionais inesperadas e envolve emoções que suscitam questionamentos e surpresa, levando-a, muitas vezes de maneira involuntária, a questionamentos, cuja consequência é a exigência da disponibilidade afetiva e capacidade de discernir suas reações interiores (TARDIF, 2000; 2010).

É fundamental reconhecer que os professores têm parte importante dos saberes em sua própria história de vida. Como nenhum outro profissional, os docentes "[...] ficaram imersos em seu lugar de trabalho durante aproximadamente 16 anos (em torno de 15.000 horas)" (TARDIF, 2010, p. 68).

Mais especificamente com relação aos docentes da educação básica, deveriam ser introduzidos, então, dispositivos de valorização da prática profissional, que são diferentes da lógica que orienta os saberes no meio universitário (TARDIF, 2010). Nessa acepção, Roldão (2005, p. 111) ressalta os escassos mecanismos de controle que vêm do interior da classe docente. A quase nula valorização dos saberes provenientes da experiência, o saber próprio do grupo dos professores da educação básica, seria um 
dos elementos que dificulta "[...] a constituição de coletivos autônomos dos agentes de ensino", o que influencia na capacidade de ser um grupo profissional que se auto-organiza.

\section{Formação inicial e continuada}

Paralelamente às reflexões sobre os saberes docentes, outra realidade se impõe como tema obrigatório de reflexão e de intervenção quando se fala de carreira docente: a formação inicial e continuada.

É importante para o desenvolvimento profissional do professor uma formação inicial forte e um contínuo desenvolvimento profissional, o que envolve uma mudança na perspectiva de formação de professores. O Holmes Group (1995), fazendo uma análise da educação nos Estados Unidos, verifica e expõe em seu relatório que muitas instituições de formação inicial oferecem uma formação fraca, o que ocasiona a entrada de pessoas mal preparadas e/ou inadequadas para a profissão docente.

No entanto, a formação de professores não se dá apenas nos bancos das universidades. Tardif, Lessard e Lahaye (1991) chamam atenção para a necessidade de tornar a prática fonte de formação, além de instaurar normas de acesso à docência e estabelecer um elo entre os níveis de ensino: olhando a prática profissional como um lugar original de formação e de produção de saberes; tornar a formação dos professores mais sólida intelectualmente; instaurar normas de acesso à profissão; estabelecer uma ligação entre as instituições universitárias de formação de professores e as escolas.

No mesmo espectro, Nóvoa (2011) propõe três medidas para que os discursos sobre a melhoria da carreira docente seja colocada em prática. A primeira delas relaciona-se justamente ao que o título dessa seção faz referência: introduzir a formação de professores para dentro da profissão. Isso significa que os próprios professores deveriam ter um lugar predominante na formação dos seus colegas. O autor toma como exemplo os médicos, os hospitais escolares e o modo como a sua preparação 
foi pensada nas fases de formação inicial, de indução e de formação em serviço: "O grupo observou sete doentes, estudando cada caso como uma 'lição'. Havia um relatório sobre o paciente, uma análise da situação, uma reflexão conjunta, um diagnóstico e uma terapia" (NÓVOA, 2011, p. 18).

Esse exemplo pode servir de inspiração para a docência, pois demonstra um modelo de como refletir coletivamente, com foco na melhoria da prática. Desse modo, Nóvoa (2011) propõe um sistema semelhante para a formação de professores, por meio do estudo aprofundado de cada caso, principalmente dos casos de insucesso escolar; de uma análise coletiva das práticas pedagógicas; da obstinação e persistência profissional para responder às necessidades e anseios dos alunos; do compromisso social e vontade de mudança. De fato, parecem medidas apropriadas para tornar o espaço da escola como parte fundamental da formação.

A reflexão coletiva é fundamental para dar sentido ao desenvolvimento profissional, mas é preciso que os professores tenham suporte para refletir, tempo previsto para isso: "É inútil reivindicar uma formação mútua, inter-pares, colaborativa, se a definição das carreiras docentes não for coerente com este propósito" (NÓVOA, 2011, p. 22).

A segunda medida seria a de promover novos modos de organização da profissão, o que envolve uma real autonomia para os docentes, real porque quanto mais "[...] se fala da autonomia dos professores mais a sua acção surge controlada, por instâncias diversas, conduzindo a uma diminuição das suas margens de liberdade e de independência" (NÓVOA, 2011, p. 20). Zeichner (1993) também reconhece a necessidade de autonomia dos docentes com relação a sua profissão.

É necessária, então, uma reestruturação dos modos de colaboração na escola, um dos elementos considerados essenciais para uma efetivação da profissão docente. Não é possível que haja uma cultura colaborativa forte se as estruturas administrativas se sobrepõem ao ensino, se são superiores, se os professores não refletem sobre as suas práticas de ensino e trabalhem para atender a demandas formuladas por outros, assim, tornam-se coadjuvantes, perdendo as suas metas e os objetivos que almejam alcançar (ZEICHNER, 1993). 
A terceira medida diz respeito ao reforço da dimensão pessoal e presença pública dos professores para que se construam percursos significativos de aprendizagem ao longo da vida, o que não deve ser confundido com obrigação de aprender ao longo da carreira, uma das justificativas sob que se assenta a proliferação dos cursos de formação contínua. Nóvoa (2011) identifica que:

Muitos programas de formação contínua têm-se revelado inúteis, servindo apenas para complicar um quotidiano docente já de si fortemente exigente. É necessário recusar o consumismo de cursos, seminários e acções que caracteriza o actual "mercado da formação" sempre alimentado por um sentimento de "desactualização" dos professores. A única saída possível é o investimento na construção de redes de trabalho colectivo que sejam o suporte de práticas de formação baseadas na partilha e no diálogo profissional (NÓVOA, 2011, p. 23).

Cabe lembrar que a necessidade de uma formação sólida e contínua vem sendo discutida há certo tempo, mas não pelos professores. Nóvoa (1999) mostra que a retórica abundante sobre o papel fundamental dos professores é produzida por políticos e intelectuais, mas não pelos próprios professores, o que implica na construção de ideia de profissão docente que, não raro, não corresponde à intencionalidade de valorizá-la. As ambiguidades, afirma o autor, são permanentes: os professores são olhados com desconfiança ao mesmo tempo em que são considerados elementos essenciais para a melhoria da qualidade de ensino e para o progresso social e cultural (NÓVOA, 1999, p. 13-14).

A observação, bastante pertinente, de Nóvoa é a de que os professores não falam sobre si, os outros o fazem. É preciso que os professores reconheçam seus saberes práticos como legítimos, para trazer a formação contínua para dentro da profissão (NÓVOA, 1999; 2011).

Nóvoa (2011) alerta que, após quarenta anos de certa invisibilidade, os professores voltaram à ribalta educativa, a partir dos anos 1980, quando importantes estudos apontaram para a questão das aprendizagens. O autor vem relatando já há algum tempo, que o excesso de discurso 
sobre má-formação dos professores tem mascarado a pobreza das práticas da formação docente e da prática docente no cotidiano escolar e estimulado um mercado de formação, altamente lucrativo (NÓVOA, 1991).

O Holmes Group (1995) reconhece essa situação nos Estados Unidos, afirmando, em seu relatório Tomorrow's Schools of Education, que a formação de professores é um grande negócio onde há muitos professores, tendo se constituído, então, boa oportunidade de mercado.

Para além do mercado da formação, há o problema latente da docência ainda estar em processo de profissionalização, um processo que não é recente, "[...] desde os anos de 1980, a profissionalização constitui certamente a transformação mais substancial que se faz necessária na educação" (TARDIF, 2013, p. 552).

O que se pode entender por saberes docentes? Aqueles efetivamente utilizados em seu trabalho para desempenho de suas tarefas: provenientes da formação profissional — transmitidos pelas instituições de formação de professores, por meio da ligação dos conhecimentos à prática do professor; do saber disciplinar — saberes integrados nas universidades, sob forma de disciplina; saber curricular — discursos, objetivos, conteúdos e métodos na forma de programas escolares que os professores devem aprender a aplicar; por fim, o saber experiencial - baseados em seu trabalho cotidiano e no conhecimento de seu meio de atuação.

A formação dos docentes é fundamental para sua prática? Sim. Quando se responde afirmativamente, pensa-se na formação que se dá em diversos espaços (inclusive na sua própria trajetória de vida), para além da universidade e dos cursos de formação, que também são fundamentais.

Uma formação pela prática é possível? Sim, e necessária. Ao considerar que há formação pela prática, o espaço da escola é resignificado, permitindo o olhar para as situações concretas da ação. Por isso, uma das possibilidades apontadas por Tardif (2000) consiste na transferência de parte da formação inicial para o próprio meio escolar.

A partir disso, pressupõe-se que os professores possuam saberes e um saber-fazer que lhes são próprios, por isso, os docentes mais experientes poderiam auxiliar os mais novos, porque estão aptos pelos 
saberes acumulados na experiência (fonte de teoria válida), a repassar conhecimentos profissionais.

A insatisfação dos Professores da Educação Básica com o magistério é apontada pela pesquisa de Lapo e Bueno (2003). Os dados obtidos em sua pesquisa permitiram constatar que de 1990 a 1995 houve um aumento da ordem de $300 \%$ nos pedidos de exoneração no magistério público em São Paulo, com um crescimento médio anual de $43 \%$.

A partir dessa constatação, as autoras buscaram entrevistar, por meio de questionário escrito, 158 ex-professores que haviam solicitado exoneração, buscando obter alguns dados preliminares: idade, tempo de serviço na rede estadual de ensino, motivo(s) para a exoneração e a atual profissão. Do total de questionário enviados, retornaram 29 questionários preenchidos, cujos dados permitiram traçar um perfil dos ex-professores:

Primeiramente, confirmaram que o magistério é um espaço de trabalho predominantemente feminino, de vez que dentre esses 29 ex-professores, 22 são mulheres. Além disto, indicam que uma parcela das mulheres está deixando a profissão docente ou, pelo menos, o ensino médio público, com a ambição de trabalhar no ensino superior ou, quiçá, em outras profissões, já que, no tocante à escolaridade, a maioria do grupo (22) continuou os estudos em nível de pós-graduação. Ao pedirem exoneração, 11 possuíam curso de especialização; 7, o mestrado; e 4, o doutorado. O que se percebe, comparando a data em que esses professores saíram da rede pública com a data de término dos cursos de pós-graduação, é que o pedido de exoneração acontece próximo do final desses cursos ou logo após a sua conclusão. Nesses casos, os motivos dos pedidos de exoneração são dois: o diploma de pós-graduação abre novas perspectivas e amplia as oportunidades no mercado de trabalho; a pequena valorização, na carreira do magistério público, dos professores que possuem a pós-graduação (LAPO e BUENO, 2003, p. 70-71, grifo nosso).

Antes de traçar a fuga, os professores entrevistados por Lapo e Bueno (2003) permaneceram na rede pública, já que quase todos pediram a exoneração após, no mínimo, cinco anos de exercício profissional, sendo que a maioria só o fez após dez anos de trabalho na rede pública. 


\section{Considerações finais}

É necessário problematizar a questão da importância da universidade tomar para si a ideia de que a formação de professores é uma de suas responsabilidades, assim como o desenvolvimento da pesquisa acadêmica. A distância entre os docentes do Ensino Superior e da educação básica faz com que muitos dos professores da Educação Básica tenham como rota de fuga a área acadêmica, ainda que se identifiquem com as atividades da educação básica, em busca de melhor remuneração e condições de trabalho.

O argumento da formação continuada deu margem ao desenvolvimento de um amplo campo lucrativo: o da venda de cursos dessa natureza, sem que, necessariamente, tenham a qualidade requerida para que o professor se mantenha atualizado. Neste sentido, a proposta de uma formação dentro da docência parece uma saída profícua, além de valorizar os saberes dos professores que já atuam na etapa da educação básica. No modelo do que fazem outros cursos, como a medicina, em que os profissionais mais experientes são fundamentais para a formação dos iniciantes.

Caso algo não seja feito, assistir-se-á ao desinteresse dos jovens e abandono da atividade docente por parte dos professores da Educação Básica, absenteísmo (ESTEVE, 1992), como resposta ao processo de insatisfação constituído por diversos fatores ligados ao percurso da atividade do magistério e a intensificação do problema do lucro sob uma ideia que deveria estar relacionada à melhora da qualidade do ensino, a formação continuada, mas se torna um produto.

\section{Referências}

ARROYO, M. G. Condição docente, trabalho e formação. In: SOUZA, J. V. A. (Org.). Formação de professores para educação básica: dez anos de LDB. Belo Horizonte: Autêntica, 2007. p. 191-209. 
CORREA, B. C. Educação infantil. In: Romualdo Portela de Oliveira e Theresa Adrião. (Org.). Organização do ensino no Brasil - níveis e modalidades na Constituição Federal e na LDB. $2^{\text {a }}$ ed. São Paulo: Xamã, 2007, p. 13-30.

CUNHA, M. I. O lugar da formação do professor universitário: o espaço da pós-graduação em educação em questão. Revista Diálogo Educacional, Curitiba, v. 9, n. 26, p. 81-90, jan./abr. 2009.

CUNHA, M. I. Trajetórias e lugares da formação da docência universitária: da perspectiva individual ao espaço institucional. Araraquara: Junqueira e Marin Editores, 2010.

ESTEVE, J. M. O Mal-Estar Docente. Lisboa: Escher / Fim de Século Edições, 1992. FIDALGO, F. S. Trabalho e carreira docente: contribuições teórico-metodológicas. Trabalho \& Educação, p. 94-109, 1996.

FREIDSON, E. Renascimento do profissionalismo. Trad. Celso Mauro Paciornik. São Paulo: Editora USP, 1998.

HOLMES GROUP. Tomorrow's Teachers: a Report of the Holmes Group. East Lansing, MI: The Holmes Group, 1995.

LAKATOS, M. E.; MARCONI, M. de A. Metodologia do Trabalho Científico. 4 ed. São Paulo, Revista e Ampliada, Atlas, 1992.

LAPO, F. R.; BUENO, B. O. O abandono do magistério: vínculos e rupturas com o trabalho docente. Psicologia USP, v. 13, n. 2, p. 243-276, 2002.

LIMA, T. C. S. de; MIOTO, R. C. T. Procedimentos metodológicos na construção do conhecimento científico: a pesquisa bibliográfica. Rev. Katál. Florianópolis v. 10, n. esp., p. 37-45, 2007.

MELLO, G. N. Magistério de $1^{\circ}$ Grau: da competência técnica ao compromisso político. São Paulo: Cortez, 1982.

NÓVOA, A. Os professores na virada do milênio: do excesso dos discursos à pobreza das práticas. Educação e Pesquisa, São Paulo, v. 25, n. 1, p. 11-20, jan./jun. 1999. 
NÓVOA, A. O Regresso dos Professores. Pinhais: Melo, 2011.

SALVADOR, A. D. Métodos e técnicas de pesquisa bibliográfica. Porto Alegre: Sulina, 1986.

SOUZA, D. T. R. de. Formação continuada de professores e fracasso escolar: problematizando o argumento da incompetência. Educação e Pesquisa, São Paulo, v. 32, n. 3, dez. 2006.

SCHWARTZMAN, S. A universidade primeira do Brasil: entre intelligentsia, padrão internacional e inclusão social. Estudos Avançados [online]. 2006, v. 20, n. 56, p. 161-189. ISSN 0103-4014. Disponível em <http://www.scielo.br/pdf/ea/ v20n56/28633.pdf>. Acesso em 29 abr. 2016.

TARDIF, M. Saberes Profissionais dos professores e conhecimentos universitários: elementos para uma epistemologia da prática profissional e suas consequências em relação à formação para o magistério. Revista Brasileira de Educação, Rio de Janeiro, n. 13, jan/fev/mar/abr, p. 5-24, 2000.

TARDIF, M. Saberes docentes e formação profissional. 10 ed. Petrópolis, RJ: Vozes, 2010.

TARDIF, M. A profissionalização do ensino passados trinta anos: dois passos para a frente, três para trás. Revista Educ. Soc., Campinas, v. 34, n. 123, p. 551-571, abr.-jun. 2013.

TARDIF, M.; LESSARD, C.; LAHAYE, L. Os Professores face ao Saber: esboço de uma problemática do saber docente. In: Teoria e Educação. v. 4, 1991.

ZEICHNER, K. A formação reflexiva de professores: idéias e práticas. Lisboa: Educa, 1993.

Recebido: 18/10/2015

Received: 10/18/2015

Aprovado: 20/05/2016

Approved: 05/20/2016 